\title{
REDUCING MAINTENANCE COSTS FOR BALLASTED TRACK: EVIDENCE FROM BRITAIN
}

\author{
ALEJANDRO ORTEGA, SIMON BLAINEY \& JOHN PRESTON \\ Transportation Research Group, University of Southampton, United Kingdom.
}

\begin{abstract}
Over the last twenty years, the railways in Britain have seen rapid growth, with patronage doubling and the level of train service increasing by $50 \%$. However, these successes have also led to challenges. In particular real unit costs are estimated to have increased by 50\%, with particularly marked increases in infrastructure renewal and enhancement costs. Against this background, the University of Southampton have been leading the Track 21 and Track to the Future projects, funded by the Engineering and Physical Sciences Research Council. These projects are assessing how to make ballasted track systems more durable given higher traffic levels and how to reduce the costs of maintenance and renewal.

Track 21 considered a number of engineering interventions of which this paper focusses on one, under sleeper pads (USPs). The cost implications of this intervention are assessed for the South West Main Line using an industry-specific model, VTISM (vehicle track interaction strategic model), adapted in two ways. First, the results of laboratory experiments from specialist test rigs are incorporated into the model. Secondly, the wider effects of increased reliability, improved ride quality and reduced vibration are also considered within a cost-benefit analysis framework. It is found that USPs can lead to substantial financial savings and, depending on assumptions concerning noise impacts, are likely to have substantial wider social benefits.
\end{abstract}

Keywords: CBA, maintenance costs, under sleeper pads

\section{INTRODUCTION}

Track 21 and its successor Track to the Future are projects funded by the UK Engineering and Physical Sciences Research Council (EPSRC) which explore several innovative interventions which are intended to deliver better engineering, economic and environmental performance of railway track (see more information on http://www.track21.org.uk/). As part of a good transport planning process, every transport infrastructure investment should be subject to some kind of economic appraisal. Cost benefit analysis (CBA) is the most commonly used tool for this purpose. When applying these tools, cost modelling is a crucial issue because it helps to determine the value of cost to be used. This financial valuation might have an important effect on the outputs of the analysis (see, for instance, Ortega et al. [1]). In the case of railways, potential advances in track and sub-base construction and maintenance can lead to improvements in reliability or reductions in perceived noise, for example. The values adopted for these parameters could influence the result and profitability of track upgrades, with errors having the consequence of misperceptions of the return gained from investment. In order to conduct such an economic appraisal, a review of the valuation of some of the most relevant parameters was carried out as the first stage of this research, before using the findings to inform modelling of track system costs.

The remainder of this paper is divided into five sections. Firstly, a review of values of noise is provided. Secondly, values of vibration and ride quality are given. Thirdly, a review

This paper is part of the proceedings of the 15th International Conference on Railway Engineering Design and Operation (COMPRAIL)

www.witconferences.com 
of reliability and journey time is undertaken. Fourthly an illustrative application of the cost modelling methodology for the South West Main Line in the UK is provided. Finally, derived from this review, we are able to offer a set of conclusions for policy makers.

\section{VALUES OF NOISE}

Noise cost estimates can be difficult to generalize due to their local nature and dependence on background noise levels [2]. Furthermore, the impact of a given noise level will depend on people's activities and their attitudes towards the railway, and as people become accustomed to a given level of noise exposure their annoyance level may decrease [3]. Four different methods were used in the studies reviewed to evaluate the cost of noise, including hedonic pricing (HP), i.e. the real market is used to obtain the economic value of one particular feature, willingness to pay (WTP) and contingent valuation (both generally carried out through stated preference (SP) surveys), and finally estimation of abatement costs. Willingness to pay values may be derived from HP as well as from SP surveys, although as Strand and Vagnes [4] point out there are a number of problems associated with such a derivation. In general, noise nuisance valuations obtained through HP methods tend to be larger than those from SP methods such as Contingent Valuation Method (CVM) or Stated Choice (SC) experiments. In fact, there are also differences between CVM and SC [5]. In addition, Janic [6] considered that the cost of noise can be calculated as the marginal cost of setting up noise protection barriers, with evidence suggesting that each barrier could reduce noise over a range of 8-10 $\mathrm{dB}$ [7]. Finally, it is worth noting that there was also little consistency between the formats in which the results were presented. These groups are cost of annoyance per person, property value depreciation, marginal cost of additional vehicles and other valuations.

\section{VALUES OF VIBRATION, RIDE QUALITY AND COMFORT}

Despite an extensive search, relatively few studies which assigned financial values to vibration or ride quality could be found. This might be explained by the fact that passenger comfort and perception of service quality are affected by several factors [8], such as time, country, culture or the physical condition of passengers, and when the subjective contribution from all aspects is approximately the same then the optimum level of comfort will be achieved [9], regardless of the relative contribution of different factors. Schwanitz et al. [10] identified the four most important attributes of comfort as being odour, air quality, air ventilation and temperature. Moreover, users have a higher sensitivity to vertical acceleration than to longitudinal or transversal acceleration [11].

The first research found giving financial valuations of ride quality was based on both RP and SP methods and focussed on alternative types of rolling stock [12]. The research analysed seating comfort, ambience, ride quality, seating layout, ventilation and noise. The former three aspects were found to be the most important aspects with a valuation ranging from $3.41 \%$ to $5.22 \%$ of the single fare for seating comfort, $1.88 \%$ to $3.05 \%$ for ambience and $1.89 \%$ to $3.06 \%$ for ride quality. However, in a literature review conducted by Johnson et al. [13], higher valuations were given for the case of trams. Although a packaging effect has been demonstrated and could therefore mean that the valuation of individual attributes is too high, this effect does not impact on the rank of each attribute in relation to the others and the classification of [13] was also obtained by the same authors [14]. Paulley et al. [15] found that refurbishment which changed train characteristics from those associated with old 'slam door' stock to new air-conditioned stock in SE England were worth around $2.5 \%$ of the fare paid, with most train refurbishments worth somewhat less than this $(\sim 1.5 \%)$. Finally, the Passenger Demand Forecasting Handbook (PDFH) [16] measured improvements in ride 
quality in terms of a decrease in in-vehicle time (IVT). Going from an extremely bumpy ride to a very smooth ride would lead to a benefit equivalent to $3.3 \%$ of IVT (commuting) to $3.7 \%$ (business/leisure), whereas going from an extremely bumpy ride to a train with a lot of movement would have benefits of $2.4 \%$ and $2.6 \%$ of IVT.

\section{VALUES OF RELIABILITY}

Frequency of travel may affect perceptions of reliability, with regular passengers likely to have a clear idea of reliability levels on their usual services, while infrequent travellers are more likely to be influenced by their most recent journey (however atypical) or by press reports and hearsay [16]. Bates et al. [17] suggested that a multiplication factor of 2.5 for delay minutes was a reasonable measure of the direct disutility of delays but also pointed out that this was an average value based on passengers having full knowledge of random delay distributions and concealing a range between 1 and 5 depending on journey length and purpose. Chang [18] recommended including in the CBA a value of journey time reliability which depends on the type of user, i.e. interregional or urban and working or non-working.

Most studies of the demand impacts of reliability have been based on SP methods. After a comparison between implied elasticities by SP valuations of late time and directly estimated lateness elasticities, Wardman and Batley [19] concluded that implied lateness elasticities are considerably higher than those which are directly estimated. Apart from overvaluation of lateness, there are other reasons which can help to explain these results such as the possibility that despite poor service performance rail travellers are unwilling or unable to reduce their rail travel. Preston et al. [20] hypothesized that users may have got used to a certain level of delay or be more tolerant to delays due to a high degree of delay associated with road travel. One of the few investigations based on RP data, conducted by Rail OR [21], looked at three significant runs of poor performance on the London-Northampton line using TRUST and CAPRI data, deriving implied multiplication factors which were around the generally accepted figure of 2.5 .

\section{CASE STUDY: THE SOUTH WEST MAIN LINE}

The South West Main Line is a railway route between London Waterloo and Weymouth on the south coast of England. It was built in the 19th century and is one of the most used lines in the UK. London is the origin or destination of approximately $90 \%$ of all journeys, trains operate at medium to high speed, and there are important proportions of freight and commuter traffic. In this paper we are going to analyse the economic effect of installing under sleeper pads (USPs) in the stretch between Portsmouth and London Waterloo. For these calculations we only consider passengers from the main stations in the corridor which are at least $30 \mathrm{~min}$ journey time to/from Waterloo (i.e. Portsmouth Harbour, Portsmouth \& Southsea, Fratton, Havant, Petersfield, Haslemere, Guildford and Woking). The length of the stretch considered is approximately 74 miles, the project life for the analysis is 60 years, the initial year 2009 and the discount rate $3.5 \%$. Table 1 offers the values we suggest should be used for this route:

Table 1: Suggested valuations for the SWML.

\begin{tabular}{lll}
\hline Parameter & Measure & Value \\
\hline Noise & $\begin{array}{l}£ \text { per dB of household affected per } \\
\text { annum }\end{array}$ & $£ 20$ (Year 2009) \\
Comfort/ride quality & Value per passenger & $1 \%$ of the ticket price \\
Reliability & $\begin{array}{l}\text { Value of late time (value in minutes } \\
\text { per minute of average lateness) }\end{array}$ & $\begin{array}{l}2.5 \text { times value of travel } \\
\text { time on average }\end{array}$ \\
\hline
\end{tabular}


The effect stemming from the installation of USPs can be split into installation cost of USPs, track maintenance, rolling stock, noise, comfort/ride quality and reliability. The methodology carried out to calculate the cost of each impact is explained within the next paragraphs:

- Investment. This is the cost of installing USP. We assume a hypothetical renewal of the whole stretch in the initial modelled year, 2009. By multiplying the number of sleepers by the unit cost of each sleeper the investment is obtained. There are 91 sleepers per $55.21 \mathrm{~m}$ of single track [22]. Taking also into account switches, and crossings and stations we assume that 400,000 USPs will be installed. We know from the Track 21 project that the unit cost per USP is $£ 15$ which leads to an investment of $£ 5.9$ million.

- Track maintenance and renewal. The cost of track maintenance and successive renewals, also known as life cycle cost, is given by the vehicle track interaction strategic model (VTISM) [23]. VTISM calculates the cost for the stretch London-Woking-Portsmouth if $40 \%$ of that route is renewed at the base year. By recalculating the average cost of the whole route (i.e. for illustrative calculations we multiply the result by 2.5) and applying the updated average cost the impact of track maintenance is determined. According to the lab tests conducted by Le Pen [24] the local track section modifier (LTSF) would be reduced by $25 \%$ after the installation of stiff USPs of $4 \mathrm{~mm}$ thickness and the main benefit would arise from an increased service life of the track and a reduced maintenance and renewal volume [25]. After the hypothetical investment not many renewals would be needed on the route, but VTISM considers additional renewals in some stretches along the infrastructure life. Therefore, in order to be conservative in our analysis we introduced the cost of installing USPs in each successive renewal calculated by VTISM, which is roughly an increase of $3 \%$ for each renewal. We estimate a benefit of around $£ 45$ million in terms of reduced maintenance and renewal costs.

- Rolling stock. Based on the results from VTISM under the USPs scenario around 10\% more rail renewals would be needed. However, we have not been able to find any evidence that more rail renewal could lead to a deterioration of rolling stock. Therefore, we have decided to leave it out of the analysis.

- Noise. We estimated with ArcGIS that in 2009 there were slightly above 108,000 buildings within $300 \mathrm{~m}$ of the track and 30,500 within $80 \mathrm{~m}$ of the track. These buildings were therefore assumed to be affected by air-borne noise and ground-borne noise, respectively [26]. Moreover, the use of USPs could lead to a reduction of ground noise of up to $15 \mathrm{~dB}$ [27] but would slightly increase air-borne noise [28]. For those buildings within $80 \mathrm{~m}$ the dominant effect may be reduction in ground-borne noise whereas for those houses between 80 and $300 \mathrm{~m}$ the increase in air-borne noise would be the dominant impact. Noise and vibration due to ground-borne noise are more annoying than just air-borne noise, albeit taking into account there are no monetary values for ground-borne noise, we have to assume this has the same valuation as air-borne noise. In order to be conservatives we have adopted a reduction of $5 \mathrm{~dB}$ in ground-borne noise and an increase of $1 \mathrm{~dB}$ in air-borne noise. The annual increase in the number of houses and in the values for noise has been chosen from [29]. We selected these values because are they lower than the WebTAG (transport analysis guidance in the UK) parameters. By multiplying the reduction of noise per house, the number of houses and the value of noise per house in each year we obtain the balance for this externality.

- Comfort/ride quality. USPs would also reduce noise inside the train and improve ride quality due to the reduction of vertical acceleration [30] but would have no impact on 
other attributes of comfort. The value of changing from a very uncomfortable to a very comfortable ride could be up to $10 \%$ of the ticket price. Thus, and according to the literature review, the value chosen for an increase in comfort as a result of installing USPs is $1 \%$ of the ticket price. We have differentiated between anytime or full, season, and off-peak or cheapest tickets. Commuters pay season ticket in a proportion of $85 \% / 15 \%$ standard/ first class which is the same proportion as of seats offered in the train and use the season ticket 480 times each year. The same proportion of standard/first is applied to anytime users. However, we assume that holders of reduced tickets do not travel in first class and that $25 \%$ of travellers within this category have a card with an average discount of $33 \%$. The proportion of each type of ticket sold (full, season or reduced) is given in the Office of Rail and Road station usage database. Finally, by multiplying the number of users in each category by the percentage of their ticket price attributed to the improvement, the value of comfort/ride quality is known.

- Reliability. $30 \%$ of delays are due to track defects and networks management [31] and according to VTISM these disruptions would be reduced by around $20 \%$ after the installation of USPs, which would lead to an overall improvement in reliability of $6 \%$. Nevertheless some items of the railway infrastructure would be relatively unaffected by USPs and therefore we have decided to reduce the figure by $50 \%$, i.e. giving a final improvement of $3 \%$. We have considered that $92 \%$ of trains would arrive on time, that is within 5 min of expected time, $5.6 \%$ would be delayed up to $30 \mathrm{~min}$ and $2.4 \%$ would be cancelled or with a significant lateness [31]. The values of time have been chosen from WebTAG and depend on the type of user: working, non-working commuting and nonworking others. To conduct the appraisal, the kind of ticket was transformed into the type of user using the figures given by the Passenger Demand Forecasting Handbook (PDFH). So we linked commuting users with non-working commuting users, business users with working travellers, and finally leisure travellers with non-working other users. Taking into account all these figures the improvement of $3 \%$ in reliability generates a benefit of $£ 35$ million.

Finally, other general economic parameters such as demand, evolution of demand and Retail Price Index (RPI) have been chosen from WebTAG and the National Rail Trends (NRT) web sites. Demand growth and RPI are capped after 20 years, and their annual average values for the first 20 years are settled around $2.05 \%$ and $3.5 \%$ respectively. Following the WebTAG recommendations, RPI has been used to calculate tickets price and rolling stock investment in nominal terms, but converted afterwards into real terms through the GDP deflator.

To conduct this economic analysis some hypotheses have been assumed, and it is often remarked that risks and uncertainty are not easily taken into account in CBA assessment [32]. For instance, the level of renewals could be slightly different from that considered by VTISM because the program assumes the renewal of some stretches in the initial year instead of the renewal of the whole route, or the value of the ground-borne noise reduction or reliability improvement could also be different. So, in order to overcome the intrinsic weakness of the CBA methodology, we use a stochastic approach rather than the deterministic one that is commonly used. This is done with a Monte Carlo Simulation underpinned by a sensitivity analysis aimed at determining the level of certainty and identifying the most important parameters for policy lessons. The goal of running a Monte Carlo Simulation is to assess risk more accurately, choosing randomly modifiable values in each iteration, whereas the goal of sensitivity analysis is to know the most important parameters influencing the result. 
In order to display the range of possible outcomes, the results of the CBA are sorted and plotted as histograms and cumulative probability distribution curves (also called value at risk and gain curve (VARG)). We have run two models with different assumptions with respect to noise. In assumption (a) we only consider an increase of air-borne noise for all houses within $300 \mathrm{~m}$ of the track, whilst in assumption (b) we consider the reduction of groundborne noise for houses within $80 \mathrm{~m}$ of the track and the slightly increment of air noise for the remaining houses between $80 \mathrm{~m}$ and $300 \mathrm{~m}$ from the track. Figure 1 shows how the cumulative probability distribution curves have the shape of a cumulative normal distribution, since we selected each variable to fluctuate between minimum and maximum values according to a normal distribution. In the most likely option, the social benefits of installing USPs in the selected route would be around $£ 89$ million. The final outcome in terms of social welfare is almost always positive and fairly stable over the MonteCarlo analysis. Only the worstcase scenario under assumption (a) brings some welfare loss whilst the worst-case scenario under assumption (b) still produces a global benefit greater than $£ 135$ million. These results demonstrate that the outcome of the analysis is quite robust.
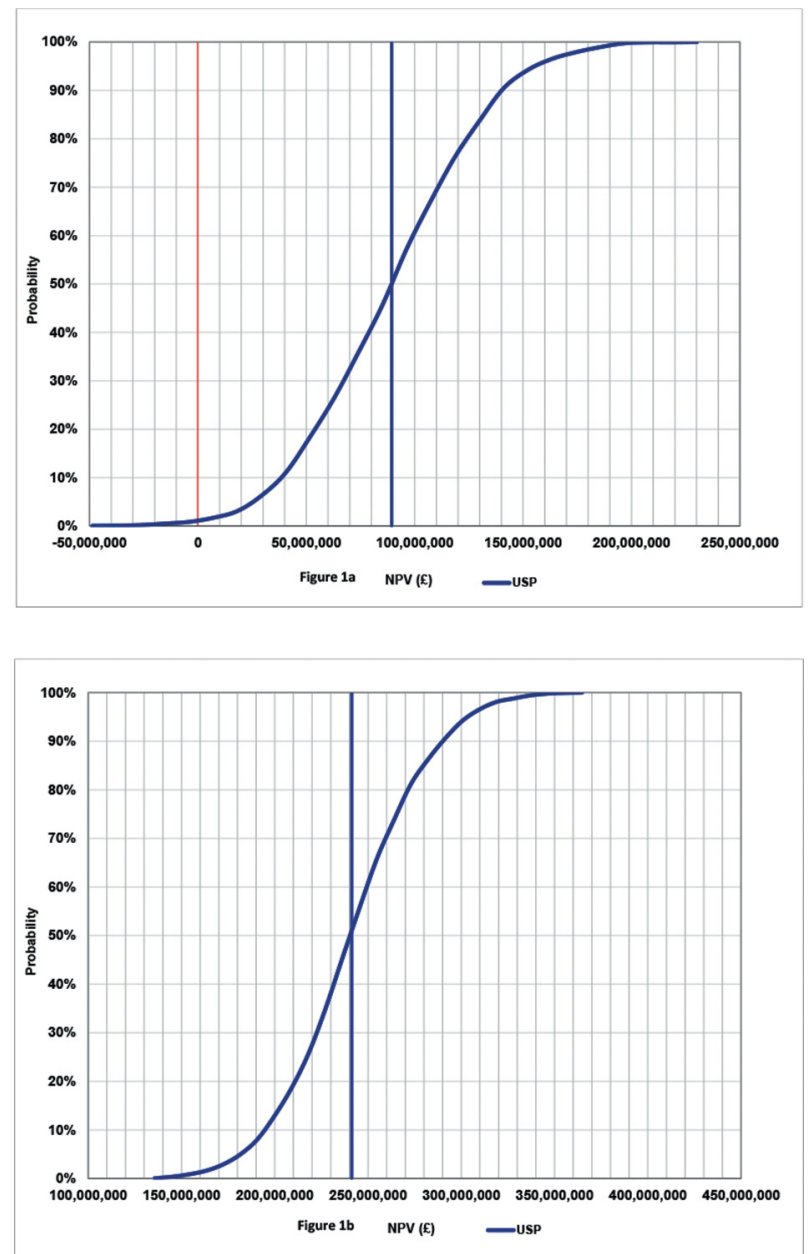

Figure 1: Net present value (NPV) cumulative distribution function. 
Two conclusions arise from the last figure. Firstly, under the majority of scenarios the expected net present value (NPV) will be always positive. Only taking into account just airborne noise (Fig. 1a) the NPV might be negative with a probability of less than $1 \%$. In fact, under this assumption the benefit can be set between $£ 38$ million and $£ 140$ million with a probability of $80 \%$ and the mean of the sample is in the middle of that range, $£ 89$ million. Under the more realistic assumption of considering that the reduction of ground-borne noise dominates for buildings within $80 \mathrm{~m}$ of the track whereas the increase of air-borne noise affects the remaining houses up to $300 \mathrm{~m}$, the benefit is even greater. The difference between the mean of both assumptions is $£ 152$ million. Secondly, there is a high variability between the minimum and the maximum value. For instance, under scenario $b$ the maximum value is almost three times higher than the minimum value. Table 2 shows the results of the two CBA carried out.

Figure 2 shows the outcome of a test carried out to analyse the sensitivity of the results to the changes of the variables studied before. The analysis was conducted through a tornado diagram to show the sensitivity of the NPV to the variables used in the methodology while keeping the remaining variables constant (Fig. 2). On the left side of this figure, we find all the variables determining the final outcome in terms of net present social value. Next to the definition of each variable, in brackets, we display the variation range tested for each variable. The variables with the largest influence on the NPV have been plotted in red, whilst the variables with little impact on the final outcome have been depicted in blue. The economic variables have been represented at the top of the figure whilst the variables that could be managed by train operating companies (TOCs) and the infrastructure manager are drawn in the middle and at the bottom of the graph.

It is noteworthy that all stakeholders benefit: train operating company, infrastructure manager, travellers and non-users. The financial benefit to Network Rail is around $£ 40$ million and might mean a risk of under-spending on maintenance given the fact that the social NPV is at least $£ 100$ million. As expected VTISM indicates that there are less interventions in the track than in the base case. The improvement in comfort and ride quality could be easily internalized through a higher ticket price and the housing market can internalize the effect of noise. The upgrades studied in Track 21 project (e.g. installation of USPs or random fibre reinforcement to name but two) are realistic and could be beneficial for the UK.

Three variables dominate the outcome: RPI, air noise increase and finally improvements in comfort/ride quality. The remaining variables have less impact on the NPV. The large influence of RPI is explained by inconsistencies with the GDP deflator and for this reason RPI is usually removed from CBA calculations. Each one $\mathrm{dB}$ increase in air-borne noise alters the NPV by almost $£ 90$ million under assumption (a) or $£ 66$ million under assumption (b). Ground-borne noise is also very important since each $1 \mathrm{~dB}$ reduction brings a benefit of $£ 25$

Table 2: NPV from the CBA parameter values.

\begin{tabular}{lcc}
\hline Probability & NPV option (a) (£ million) & NPV option (b) (£ million) \\
\hline Minimum value & -48.676 & 135.683 \\
VAR 10\% & 38.079 & 194.374 \\
Expected value (mean) & 89.331 & 241.279 \\
VAG 90\% & 140.257 & 290.150 \\
Maximum value & 230.139 & 364.720 \\
\hline
\end{tabular}



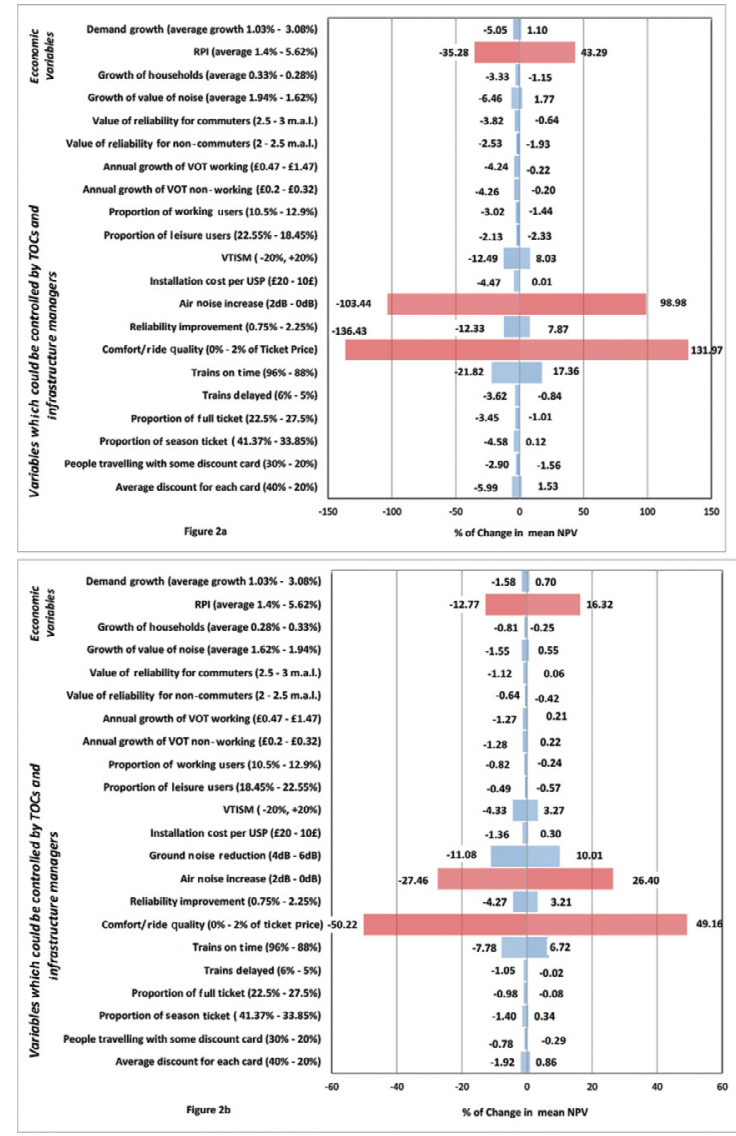

Figure 2: Sensitivity analysis.

million, mainly for the buildings within $80 \mathrm{~m}$ of the track. Any track intervention improving comfort/ride quality just by $1 \%$ of the ticket price leads to a social gain of $£ 120$ million. A reliability improvement of $1 \%$ would lead to a smaller benefit of nearly $£ 10$ million. This is also the case for the proportion of trains on time; each improvement of $1 \%$ means a NPV decrease of around $£ 4$ million. Logically, the better the punctuality of the system, the less the effect of USP, and this is what the figure is telling us. This result is based on the fact that this proportion is assumed to be constant along the infrastructure life, but different for USPs and base case. Fortunately these variables can be managed by TOCs and the infrastructure owner (i.e. Network Rail) and therefore there is room for realistic upgrades of the track. The UK railways are among the oldest in Europe and it is important that in order to avoid welfare losses from users with a high valuation of their trip or from their externalities the railway system should be upgraded to the 21 st century.

\section{CONCLUSIONS}

In order to carry out effective cost modelling of potential advances in track and sub-base construction and maintenance, and to reliably optimize the timing of maintenance interventions, it is necessary to place values on the various factors that are affected by such 
interventions. These include the effects of noise and vibration on both passengers and nonusers, and of reliability, journey time and ride quality on both passengers and rail industry stakeholders. A review of the evidence on valuations of these factors has therefore been carried out in this paper, as the basis for undertaking a meta-analysis of the valuations. It should be noted that the extent of the evidence-base was found to be highly variable, with little research having been undertaken on valuing the effect of some of the factors.

The high degree of variability can be explained by several reasons. Firstly, differences between regions, types of travellers and affected non-travellers have been found. Secondly, depending on the approach considered the value to be placed in the analysis has to be different; such is the case of ride quality which can be valued through IVT or as a percentage of the ticket price. Finally, HP methods and SP surveys usually lead to different values, whilst bias in some results can also be found.

It is also noteworthy that noise can be valued by two approaches. On the one hand, noise should be taken into account as an externality that affects non-rail users such as neighbourhoods close to a rail line. On the other hand, noise experienced by rail users must also be considered as part of passenger comfort. An example which clarifies this can be found in noise protection barriers. If noise protection barriers are installed along the track, the external effect of noise would be greatly reduced, but travellers would continue to be negatively affected by noise while also losing potential benefits gained from appreciation of the view from the train. Regarding valuation of ride quality and passenger comfort, despite the improvement on the topic, there is still a lack of consistent values and therefore further research is needed. With respect to reliability, it is well acknowledged that rail users are adversely affected by lateness. Nevertheless, some findings suggest that travellers are becoming less sensitive to delays and consequently its value should be lower.

So, in order to carry out economic appraisal and avoid misinterpretations of the results, we suggest adapting the values to the particular case study reflecting a realistic situation and also conducting a sensitivity analysis which can help identify the key parameters. Finally, in developed countries with old rail infrastructures and high demand, such as is the case in the UK, it appears that minor interventions which improve reliability and comfort/ride quality and at the same time reduce externalities could potentially bring important social benefits.

\section{REFERENCES}

[1] Ortega, A., Vassallo, J., Guzmán, A. \& Pérez-Martínez, P., Are Longer and Heavier Vehicles (LHVs) beneficial for society? A cost benefit analysis to evaluate their potential implementation in Spain. Transport Reviews: A Transnational Transdisciplinary Journal, 34(2), pp. 150-168, 2014. DOI: 10.1080/01441647.2014.891161.

[2] Nash, C., Unification of accounts and marginal costs for transport efficiency: Final report, s.l.: ITS, University of Leeds, 2003.

[3] Brons, M., Nijkamp, P., Pels, E. \& Rietveld, P., Railroad noise: economic valuation and policy. Transportation Research D, 8, pp. 169-184, 2003. DOI: 10.1016/S13619209(02)00048-2.

[4] Strand, J. \& Vagnes, M., The relationship between property values and railroad proximity: a study based on hedonic prices and real estate brokers' appraisals. Transportation, 28, pp. 137-156, 2001.

[5] Bristow, A., Wardman, M. \& Chintakayala, V., International meta-analysis of stated preference studies of transportation noise nuisance. Transportation, 42, pp. 71-100, 2015. DOI: 10.1007/s11116-014-9527-4. 
[6] Janic, M., An assessment of the performance of the European long intermodal freight trains (LIFT). Transportation Research Part A, 42, pp. 1326-1339, 2008. DOI: 10.1016/j.tra.2008.06.008.

[7] Clausen, U., Doll, C., Franklin, F.J., Franklin, G.V., Heinrichmeyer, H., Kochsiek, J., Rothengatter, W. \& Sieber, N., Reducing railway noise pollution, Brussels: European Parliament, Directorate-General for Internal Policies, 2012.

[8] Grujičić, D., Ivanović, I., Jović, J. \& Đorić, V., Customer perception of service quality in public. Transport, 29(3), pp. 285-295, 2014. DOI: 10.3846/16484142.2014.951685.

[9] Hardy, A., Measurement and assessment of noise within passengers trains. Journal of Sound and Vibration, 31(3), pp. 819-829, 2000. DOI: 10.1006/jsvi.1999.2565.

[10] Schwanitz, S., Wittkowski, M., Rolny, V. \& Basner, M., Pressure variations on a train Where is the threshold to railway passenger discomfort? Applied Ergonomics, 44(2), pp. 200-209, 2013. DOI: 10.1016/j.apergo.2012.07.003

[11] Castellanos, J. C. \& Fruett, F., Embedded system to evaluate the passenger comfort in public transportation based on dynamical vehicle behavior with user's feedback. Measurement, 47, pp. 442-451, 2014. DOI: 10.1016/j.measurement.2013.08.068.

[12] Wardman, M. \& Whelan, G., Rolling stock quality - Improvements and willingness of users to pay, s.l.: Working paper. University of Leeds, 1998.

[13] Johnson, D., Abrantes, P. \& Wardman, M., Analysis of Quantitative Research on Quality Attributes for Trams, s.1.: University of Leeds, 2009.

[14] Wardman, M. \& Whelan, G., Valuation of improved railway rolling stock: A review of the literature and new evidence. Transport Reviews: A Transnational Transdisciplinary Journal, 21(4), pp. 415-447, 2001. DOI: 10.1080/01441640010020115.

[15] Paulley, N., Balcombe, R., Mackett, R., Titheridge, H., Preston, J., Wardman, M., Shires, J. \& White, P., The demand for public transport: The effects of fares, quality of service, income and car ownership. Transport Policy, 13, pp. 295-306, 2006. DOI: 10.1016/j.tranpol.2005.12.004.

[16] Association of Train Operating Companies. Passenger Demand Forecasting Handbook v.5. London: ATOC, 2009.

[17] Bates, J., Jones, P., Polak, J. \& Cook, A., The Investigation of Punctuality and Reliability, s.l.: s.n, 2000.

[18] Chang, J.S., Assessing travel time reliability in transport appraisal. Journal of Transport Geography, 18(3), pp. 419-425, 2010. DOI: 10.1016/j.jtrangeo.2009.06.012.

[19] Wardman, M. \& Batley, R., Travel time reliability: A review of late time valuations. Transportation, 41, pp. 1041-1069, 2014. DOI: 10.1007/s11116-014-9526-5.

[20] Preston, J., Wall, G., Batley, R., Ibáñez, J. \& Shires, J., Impact of delays on passenger train services: evidence from Great Britain. Transportation Research Record: Journal of the Transportation Research Board, 2117, pp. 14-23, 2009. DOI: 10.3141/2117-03.

[21] Rail, O.R., Performance, Perceptions and Revenue, s.l.: s.n, 1996.

[22] Pieringer, A., Innovative sleeper design with under sleeper pads as an efficient method to reduce railway induced vibration propagation. Research results of RIVAS. UrbanaChampaign, Illinois, UIUC: Crosstie \& Fastening Symposium, 2014.

[23] SERCO., VTISM Version 2.6.6 User Guide, s.1.: SERCO, 2014.

[24] Le Pen, L., Proposed LTSF modification procedures. Southampton: University of Southampton, Working Paper, 2015.

[25] Marschnig, S., Lowering track lifecycle costs with sleeper pads. EURAILmag Business \& Technology, The magazine for European Rail decision makers, 23, pp. 146-147, 2011. 
[26] Zapfe, J., Saurenman, H. \& Fidell, S., Ground-Borne Noise and Vibration in Buildings Caused by Rail Transit, s.l.: TCRP, 2009.

[27] Deutsche Bahn, A. \& Hans-Joerg, T., State of the art review of mitigation measures on track. Deliverable D 3.1, s.l.: Railway Induced Vibration Abatement Solutions Collaborative project, 2011.

[28] Triepaischajonsak, N., The Effect of Sleeper Soffit Pads on Railway Noise, University of Southampton: Southampton, 2008.

[29] Nellthorp, J., Bristow, A.L. \& Day, B., Introducing willingness-to-pay for noise changes into transport appraisal: An application of benefit transfer. Transport Reviews: A Transnational Transdisciplinary Journal, 27(3), pp. 327-353, 2007. DOI: 10.1080/01441640601062621.

[30] Lakuši, S., Ahac, M. \& Haladin, I., Experimental investigation of railway track with under sleeper pad. Portoroz, Slovenian congress on the roads and traffic, 2010.

[31] Network Rail. Annual Return 2010. Moving ahead. Investing in the future, Milton Keynes: Network Rail, 2010.

[32] De Palma, A., Picard, N. \& Andrieu, L., Risk in transport investments. Networks and Spatial Economics, 12(2), pp. 187-204, 2012. DOI: 10.1007/s11067-009-9109-8. 